\title{
Balanço hídrico e classificação climática para o município de Januária - MG
}

\author{
José Ângeles Moreira de Oliveira ${ }^{*}$
}

\begin{abstract}
RESUMO: O conhecimento das características hidrológicas de uma região é fundamental, pois permite estabelecer os períodos de disponibilidade e de escassez hídrica, permitindo planejar e gerenciar o uso dos recursos hídricos. O trabalho objetivou calcular o balanço hídrico climatológico (BHC) bem como realizar a classificação climática pelo método de Thornthwaite e Mather (1955) para o município de Januária - MG. Para a realização do estudo foi utilizada uma série de dados históricos entre os anos de 1961 a 2017, relativos à precipitação média mensal e temperatura média mensal. Para o cálculo do BHC foi adotado o valor de $100 \mathrm{~mm}$ para a capacidade de água disponível (CAD). A deficiência hídrica anual no município foi de 492,1 mm, sendo distribuída entre os meses de abril a outubro totalizando sete meses de déficit hídrico. $\mathrm{O}$ excedente hídrico foi verificado apenas nos meses de dezembro e janeiro, totalizando $104,0 \mathrm{~mm}$.
\end{abstract}

Palavras-chave: precipitação, temperatura, deficiência hídrica.

\section{Water balance and climatic classification for the municipality of Januária - MG}

\begin{abstract}
The knowledge of the hydrological characteristics of a region is fundamental, as it allows you to establish periods of availability and water scarcity, allowing you to plan and manage the use of resources. The study aimed to calculate the climatological water balance (BHC) as well as performing the climate classification by the method of Thornthwaite and Mather (1955) for the municipality of Januária - MG. For the realization of the study was used a series of historical data between the years of 1961 to 2017, relating to the averages monthly precipitation and temperature. For the calculation of the BHC was adopted the value of $100 \mathrm{~mm}$ for the available water capacity (CAD). The annual water deficiency in the municipality was $492.1 \mathrm{~mm}$, being distributed between the months of April to October, totaling seven months of water deficit. The water surplus was observed only in the months of December and January, totaling $104.0 \mathrm{~mm}$.
\end{abstract}

Keywords: precipitation, temperature, water deficiency.

\section{INTRODUÇÃO}

Os recursos hídricos desempenham importante papel para a manutenção da vida, e, portanto, da existência deste recurso depende, a sobrevivência da espécie humana, a conservação e o equilíbrio da biodiversidade e as relações de dependência entre seres vivos e ambientes naturais (BACCI; PATACA, 2008). O conhecimento das características hidrológicas de uma região é fundamental, pois, permite estabelecer os períodos de disponibilidade e de escassez hídrica.

Segundo Fietz et al. (2001) o balanço hídrico climatológico (BHC) é um método muito utilizado, que permite avaliar a quantidade de água armazenada no solo e quantificar a ocorrência de déficit e excedente hídrico ao longo do tempo.

O conhecimento das variáveis de saída que compõe o BHC, permitem o planejamento agropecuário e as práticas de controle de produção, disponibilizando informações que permitem aos produtores identificar as fragilidades climáticas, sendo uma ferramenta essencial para o sucesso de um empreendimento agrícola, que inclui a decisão de optar ou não por sistemas de irrigação para suprir a deficiência hídrica no solo (SANTOS et al., 2010). Os valores resultantes do cálculo do BHC, também possibilitam realizar a classificação climática, já que os dados necessários são justamente os determinados na resolução do balanço hídrico (DANTAS et al., 2007).

A classificação climática de acordo com Andrade Júnior et al., 2005 tem o intuito de identificar em uma determinada região de estudo, zonas com características relativamente homogêneas visando fornecer informações valiosas sobre as características da região, suas potencialidades agrícolas e o meio ambiente. Existem diversos sistemas de classificação climática, dentre eles destaca-se o de Thornthwaite e Mather (1955), que utiliza índices definidos com base no balanço hídrico climático (SILVA et al., 2014). Segundo Cunha e Martins (2009) o sistema permite identificar pequenas variações espaciais climáticas.

\footnotetext{
Recebido em 15/10/2018; Aceito para publicação em 30/04/2019

${ }^{1}$ Instituto Federal do Norte de Minas Gerais

*E-mail: j.ngeles@yahoo.com
} 
A estimativa do balanço hídrico climático e a classificação climática são ferramentas indispensáveis para a determinação da aptidão de áreas para culturas agrícolas e no planejamento de sistemas de irrigação (PASSOS et al., 2017).

De acordo com dados do IBGE (2010) a cidade de Januária tem $36 \%$ de seus habitantes residentes na zona rural, possuindo uma agricultura diversificada com destaque para cultivos de banana, maracujá, abóbora, alho, cana-de-açúcar, mandioca, milho e feijão (IBGE, 2017).

Diante do exposto, o conhecimento das características da região, se torna fundamental para um melhor planejamento das atividades agrícolas, portanto, o objetivo deste estudo foi calcular o balanço hídrico climatológico (BHC) bem como realizar a classificação climática pelo método de Thornthwaite e Mather (1955) para o município de Januária - MG.

\section{MATERIAL E MÉTODOS}

O município de Januária encontra-se localizado na região sudeste do Brasil ("15²9'16”S
4421'43'O) e norte do estado de Minas Gerais, com uma área territorial de $6.661,667 \mathrm{~km}^{2}$. O solo da região estudada classifica-se como latossolo vermelho amarelo (PLANO MUNICIPAL DE SANEAMENTO BÁSICO DE JANUÁRIA, 2014), o clima é Aw (tropical com estação seca de inverno) de acordo com a classificação de Köppen, precipitação média anual superior a $750 \mathrm{~mm} \mathrm{e}$ temperatura média anual de $27{ }^{\circ} \mathrm{C}$. Possui uma população de 67.628 habitantes e área

territorial de $6.661,667 \mathrm{~km}^{2}$ (IBGE, 2018), distante cerca de $603 \mathrm{~km}$ da capital do Estado, fazendo fronteira com os municípios de Formosa, Chapada Gaúcha, São Francisco, Pedras de Maria da Cruz, Itacarambi, Bonito de Minas, Cônego Marinho e estado da Bahia (CPRM, 2014).

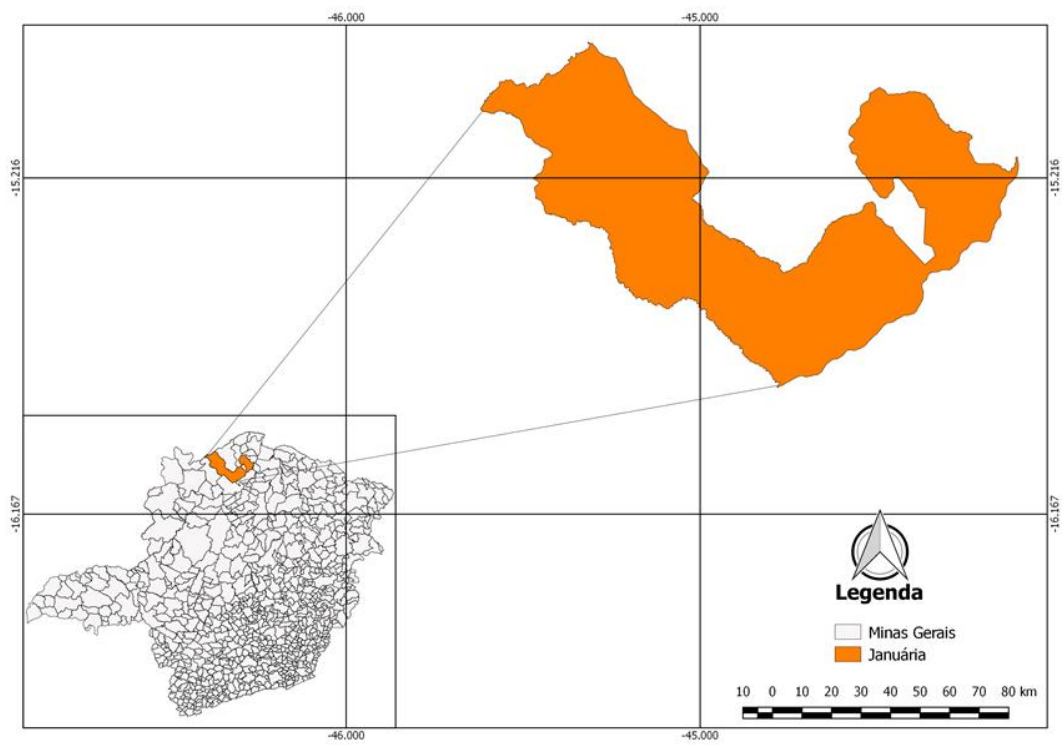

Figura 1: Mapa de localização do município de Januária - MG.

Para a realização do estudo foram utilizados valores de precipitação e temperatura do banco de dados do Instituto Nacional de Meteorologia do Brasil - INMET, do período de janeiro de 1961 a dezembro de 2017, totalizando 56 anos, fornecidos pela estação meteorológica convencional 83386 do Instituto Nacional de Meteorologia (INMET).

$\mathrm{O}$ balanço hídrico climático (BHC) foi obtido através do método proposto por Thornthwaite e Mather (1955), utilizando planilha eletrônica elaborada por Rolim et al. (1998), sendo considerados os dados médios mensais de precipitação e temperatura. Foi adotado $100 \mathrm{~mm}$ para a capacidade de água disponível no solo (CAD), valor representativo do solo encontrado na região de estudo, com alta capacidade de armazenamento, como o latossolo vermelho-amarelo do município. A evapotranspiração potencial (ETP) foi estimada pelo método proposto por Thornthwaite (1948).

Para a realização do trabalho foi seguida a metodologia de Thornthwaite e Mather (1955), que considera os dados obtidos do balanço hídrico climatológico (BHC). A classificação climática foi realizada com base nos valores dos índices hídrico 
(Ih), de aridez (Ia) e de umidade (Iu), obtidos através das equações abaixo:

$I h=\frac{E X C}{E T P} 100 \quad($ Equação 2$)$

$I a=\frac{D E F}{E T P} 100 \quad($ Equação 3$)$

$\mathrm{Iu}=\mathrm{Ih}-0,6 \mathrm{Ia} \quad$ (Equação 3)

\section{RESULTADOS E DISCUSSÃO}

O balanço hídrico climatológico (BHC) para a região de Januária-MG, está apresentado na Tabela 1 .

Tabela 1: Balanço hídrico climatológico pelo método de Thornthwaite e Mather (1955), para a cidade de Januária - MG, no período de 1961 a 2017.

\begin{tabular}{lcccccccccc}
\hline Mês & $\begin{array}{c}\mathbf{T} \\
\left({ }^{\mathbf{C}}\right)\end{array}$ & $\begin{array}{c}\mathbf{P} \\
(\mathbf{m m})\end{array}$ & $\begin{array}{c}\text { ETP } \\
(\mathbf{m m})\end{array}$ & $\begin{array}{c}\text { P-ETP } \\
(\mathbf{m m})\end{array}$ & $\begin{array}{c}\text { NEG. } \\
\mathbf{A C} \\
(\mathbf{m m})\end{array}$ & $\begin{array}{c}\text { ARM } \\
(\mathbf{m m})\end{array}$ & $\begin{array}{c}\text { ALT } \\
(\mathbf{m m})\end{array}$ & $\begin{array}{c}\text { ETR } \\
(\mathbf{m m})\end{array}$ & $\begin{array}{c}\text { DEF } \\
(\mathbf{m m})\end{array}$ & $\begin{array}{c}\text { EXC } \\
(\mathbf{m m})\end{array}$ \\
\hline Jan & 25,1 & 160,7 & 106,8 & 53,9 & 0,0 & 100,00 & 0,00 & 106,8 & 0,0 & 53,9 \\
Fev & 25,4 & 106,6 & 105,6 & 1,0 & 0,0 & 100,00 & 0,00 & 105,6 & 0,0 & 1,0 \\
Mar & 25,3 & 119,5 & 118,5 & 0,9 & 0,0 & 100,00 & 0,00 & 118,5 & 0,0 & 0,9 \\
Abr & 24,7 & 42,7 & 111,8 & $-69,2$ & $-69,2$ & 50,07 & $-49,93$ & 92,6 & 19,2 & 0,0 \\
Maio & 23,1 & 11,9 & 96,8 & $-84,9$ & $-154,0$ & 21,43 & $-28,64$ & 40,6 & 56,2 & 0,0 \\
Jun & 21,7 & 2,1 & 79,0 & $-76,9$ & $-231,0$ & 9,93 & $-11,50$ & 13,6 & 65,4 & 0,0 \\
Jul & 21,5 & 0,8 & 79,2 & $-78,3$ & $-309,3$ & 4,54 & $-5,39$ & 6,2 & 73,0 & 0,0 \\
Ago & 22,8 & 1,5 & 93,8 & $-92,3$ & $-401,6$ & 1,80 & $-2,73$ & 4,3 & 89,6 & 0,0 \\
Set & 25,2 & 7,9 & 120,3 & $-112,4$ & $-514,0$ & 0,59 & $-1,22$ & 9,1 & 111,2 & 0,0 \\
Out & 26,6 & 63,1 & 141,0 & $-77,9$ & $-591,9$ & 0,27 & $-0,32$ & 63,4 & 77,5 & 0,0 \\
Nov & 25,5 & 185,3 & 116,4 & 69,0 & $-36,8$ & 69,24 & 68,97 & 116,4 & 0,0 & 0,0 \\
Dez & 25,1 & 190,0 & 111,1 & 78,9 & 0,0 & 100,00 & 30,76 & 111,1 & 0,0 & 48,1 \\
\hline Totais & 292,0 & 892,2 & 1280,4 & $-388,1$ & - & 558 & 0,00 & 788,2 & 492,1 & 104,0 \\
\hline Médias & 24,3 & 74,4 & 106,7 & $-32,3$ & - & 46,5 & - & 65,7 & 41,0 & 8,7 \\
\hline
\end{tabular}

T: Temperatura do ar; P: Precipitação; ETP: Evapotranspiração Potencial; NEG.AC: Negativo Acumulado; ARM: Armazenamento de água no solo; ALT: Alteração do armazenamento de água no solo; ETR: Evapotranspiração real; DEF: Deficiência Hídrica e EXC: Excedente Hídrico.

Por meio dos dados obtidos no estudo para o município de Januária - (MG), verificou-se uma temperatura média anual estimada de $24,3{ }^{\circ} \mathrm{C}$, com mínima de $23,1{ }^{\circ} \mathrm{C}$ ocorrida no mês de maio e máxima de $26,6^{\circ} \mathrm{C}$ no mês de outubro.

A precipitação pluviométrica anual foi de 892,2 $\mathrm{mm}$, com distribuição irregular ao longo do ano Figura 2, mínima de $0,8 \mathrm{~mm}$ no mês de julho e máxima de 190,0 mm no mês de dezembro. Foi possível observar duas estações bem definidas, uma chuvosa, que se estendeu entre os meses de outubro e março, concentrando aproximadamente $92,5 \%$ do total acumulado e outra seca que ocorreu entre os meses de abril a setembro contribuindo com apenas $7,5 \%$ da precipitação, em relação ao total.

A evapotranspiração potencial (ETp) apresentou taxa anual total de $1280,4 \mathrm{~mm}$, com variação mínima de 79,0 mm no mês de junho e máxima de
Em que:

$\mathrm{EXC}=$ excedente hídrico, em mm;

$\mathrm{ETP}=$ evapotranspiração total, em mm;

$\mathrm{DEF}=$ deficiência hídrica, em $\mathrm{mm}$;

Ih = índice hídrico;

Ia = índice de aridez;

$\mathrm{Iu}=$ índice de umidade.

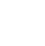




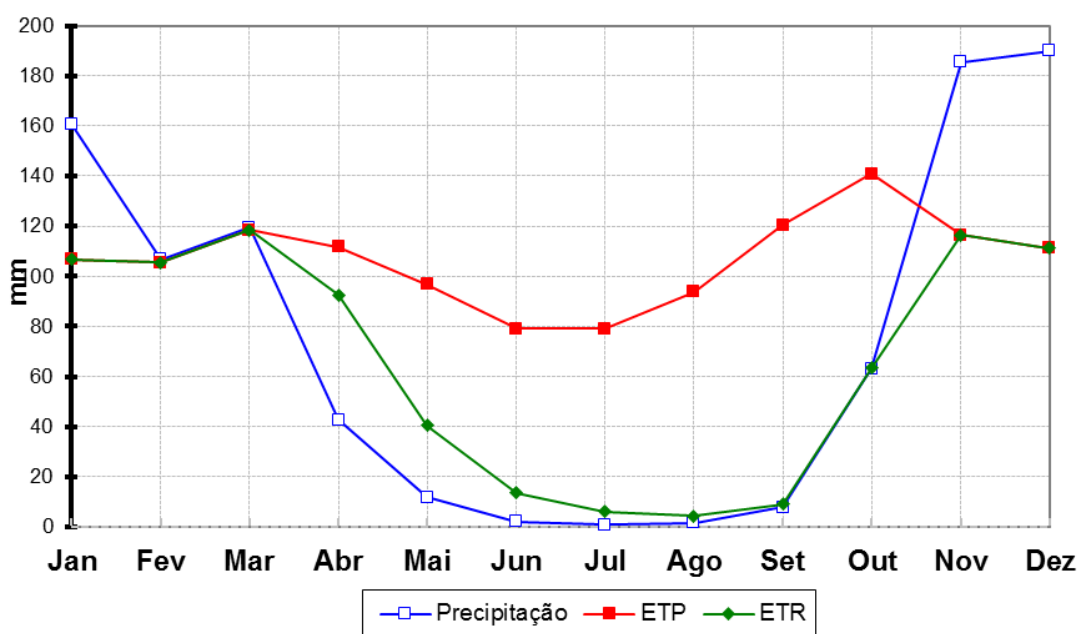

Figura 2: ETP: Evapotranspiração potencial; ETR: Evapotranspiração real. Período: 1961 - 2017.

As maiores taxas de armazenamento de água no solo, foram nos meses de dezembro a março, atingindo a capacidade máxima de armazenamento de água no solo, favorecendo a formação do excedente hídrico (Figura 3). Já nos meses de abril a outubro foi identificado as menores taxas de armazenamento variando entre 0,27 a 50,07 $\mathrm{mm}$ Tabela 1, caracterizando período de deficiência hídrica na região, tornando-se necessário a disponibilização de água através da irrigação de forma a atender à necessidade hídrica das culturas agrícolas.

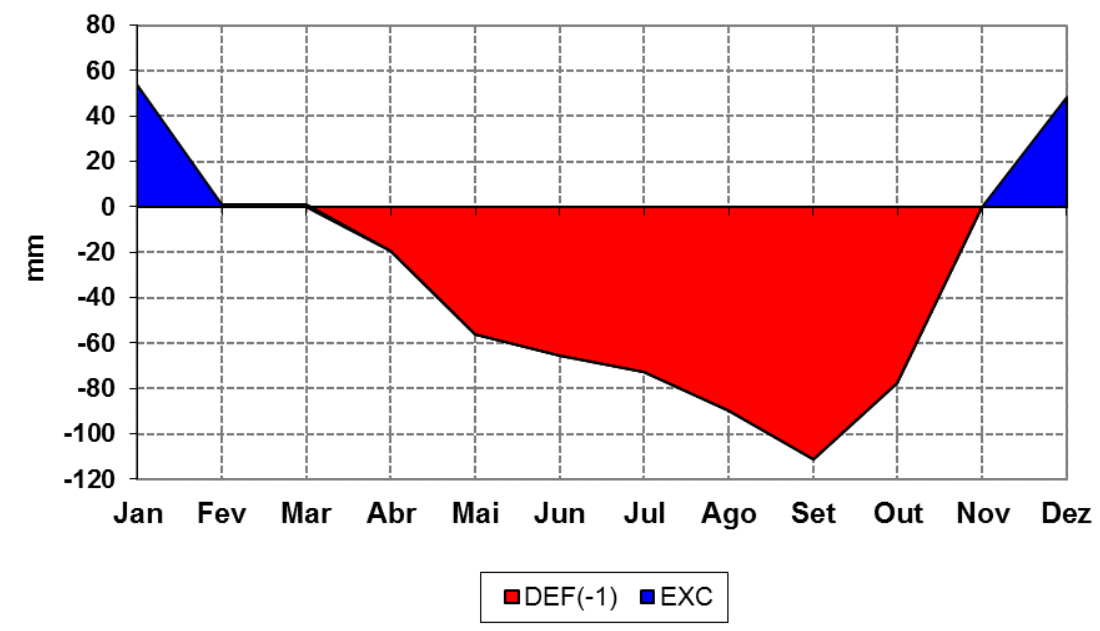

Figura 3: DEF: Deficiência hídrica; EXC: Excedente hídrico. Período: 1961-2017.

O período de deficiência hídrica ocorre entre os meses de abril a outubro (Figura 4), sendo que os meses com maior e menor deficiência hídrica são setembro com $111,2 \mathrm{~mm}$ e abril início do período de estiagem com 19,2 mm, respectivamente. A deficiência hídrica anual foi de $492,1 \mathrm{~mm}$, distribuída entre os meses de abril a outubro (Figura 4), correspondendo a sete meses de estiagem na região. O balanço hídrico apresenta deficiência hídrica devido ao fato de a evapotranspiração potencial ser maior do que as precipitações, característica marcante dos municípios da região semiárida do Brasil (Araújo, 2011). Com relação a agricultura para regiões que apresentam distribuição irregular das chuvas Ribeiro et al. (2015) recomenda um planejamento adequado da melhor época para plantio das principais culturas cultivadas em cada região, de modo que a semeadura seja feita em períodos de melhor disponibilidade hídrica para que as fases de máxima exigência hídrica da cultura não coincidam com o período de máxima deficiência de água no solo.

Observa-se ainda que na estação úmida início das primeiras chuvas mês de novembro ocorre a reposição da água no solo (Figura 4) até que esse atinja sua capacidade máxima de armazenamento de água (CAD), surgindo então o excedente hídrico nos meses de dezembro e janeiro. Nesse período, o solo 
teoricamente apresenta condições favoráveis ao crescimento e ao desenvolvimento vegetativo das

culturas agrícolas.

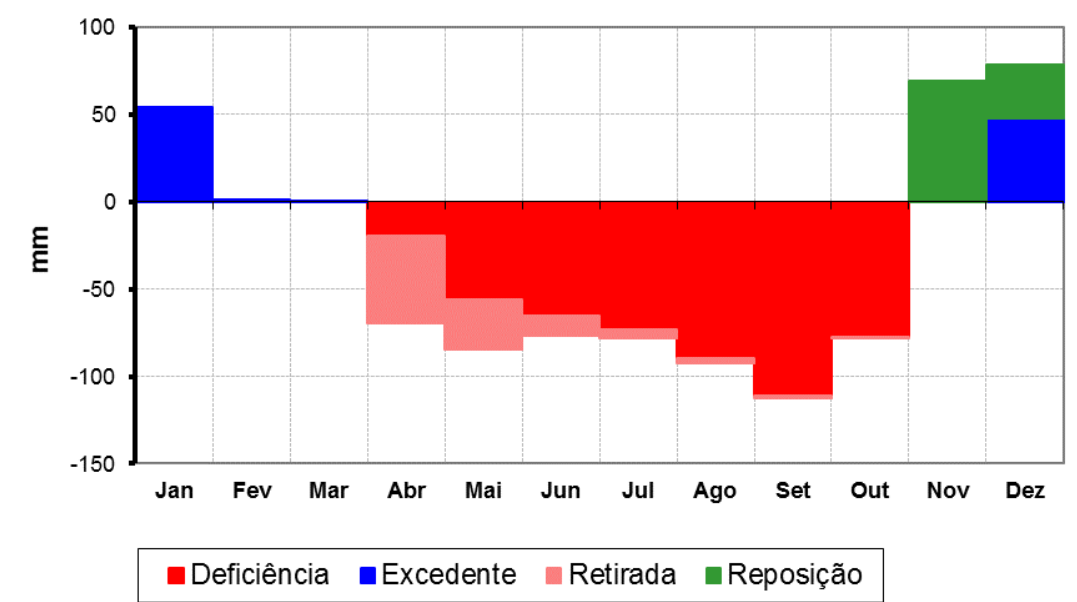

Figura 4: Extrato do balanço hídrico mensal. Método de Thornthwaite; Mather (1955). Período: 1961-2017.

A classificação climática foi obtida com base nos valores do índice hídrico, índice de aridez e índice de umidade. No índice de umidade (Iu) considerado como a "chave inicial" para a classificação, o valor de (Iu) foi de -14,93, sendo encontrado a tipologia $\mathrm{C} 1$ indicando clima subúmido seco. Em seguida por meio da "segunda chave", com base no índice de aridez (Ia) igual a 38,43 e índice hídrico (Ih) igual a 8,12 obteve-se a letra $\mathrm{w}$, caracterizando moderado excesso no verão. Já a "terceira chave" definida em função da evapotranspiração potencial anual (ETPanual) de $1280,4 \mathrm{~mm}$, determinou-se o subtipo A' que indica clima megatérmico. Por último, através da "quarta chave", em função da relação entre a evapotranspiração de verão (ETPv) igual a 442,05 mm obtida pelo somatório da ETP dos meses de (dezembro, janeiro, fevereiro e março) pela evapotranspiração anual (ETPanual) igual a 1280,4 $\mathrm{mm}$, determinou-se o subtipo a'.

Assim, a fórmula climática completa é $\mathrm{C}_{1} \mathrm{wA}$ 'a', ou seja, o clima para a cidade de Januária MG é caracterizado como megatérmico com moderado excesso hídrico no verão. A classificação realizada possui semelhança com a classificação já existente de acordo com o método de Koopen, porém, esta não diferencia os tipos climáticos perdendo em detalhes, enquanto a de Thornthwaite e Mather, além de levar em conta a temperatura, precipitação e evapotranspiração, apresenta em detalhe o período de déficit hídrico anual da localidade.

Tabela 2: Classificação climática do Município de Januária - MG. Método de Thornthwaite e Mather (1955).

\begin{tabular}{ccccc}
\hline Ih (\%) & Ia (\%) & Iu (\%) & ETP $_{\text {anual }}$ & $\begin{array}{c}\mathbf{E T P}_{\text {verõo }} / \text { ETPanual } \\
(\boldsymbol{\%})\end{array}$ \\
\hline 8,12 & 38,43 & $-14,93$ & 1280,4 & 0,34 \\
- & $\mathrm{w}$ & $\mathrm{C}_{1}$ & $\mathrm{~A}^{\prime}$ & a' \\
\hline
\end{tabular}

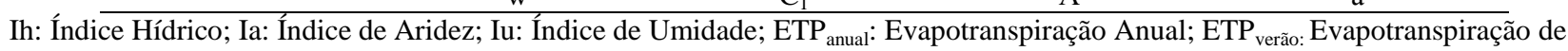
Verão.

\section{CONCLUSÃO}

1. O estudo revelou que a localidade apresenta duas estações climáticas bem definidas: chuvosa e seca.

2. A classificação climática do município evidenciou tratar-se de uma localidade com clima sub-úmido seco, megatérmico, com moderado excesso hídrico no verão.

\section{REFERÊNCIAS}

ARAÚJO, S. M. S. A Região semiárida do nordeste do Brasil: Questões Ambientais e Possibilidades de uso Sustentável dos Recursos. Rios Eletrônica, v.5, n.5, p.8998, 2011.

BACCI, D. L. C.; PATACA, E. M. Educação para Água. Revista de Estudos Avançados, v. 22, n. 63, mai./ ago. 2008.

COMPANHIA DE PESQUISA DE RECURSOS MINERAIS - CPRM. Atlas Pluviométrico do Brasil; 
Equações Intensidade-Duração-Frequência. Município: Januária/MG. Salvador, BA: CPRM, 2014.

DANTAS, A.A.A., CARVALHO, L.G., FERREIRA, E. Classificação e tendências em Lavras, MG. Ciência e Agrotecnologia, Lavras, v.31, n.6, p.1862-1866, 2007. http://dx.doi.org/10.1590/ S1413-70542007000600039

FIETZ, C. R.; URCHEI, M. A.; FRIZZONE, J. A. Probabilidade de ocorrência de déficit hídrico na região de Dourados, MS. Revista Brasileira de Engenharia Agrícola e Ambiental, v.5, n.3, p.558-562, 2001.

IBGE - INSTITUTO BRASILEIRO DE GEOGRAFIA E ESTATÍSTICA. Censo Demográfico 2010. Disponível em: <https://cidades.ibge.gov.br/brasil/mg/januaria/pesqu isa/23/47427?detalhes=true $>$. Acesso em: 18 set. 2018.

IBGE - INSTITUTO BRASILEIRO DE GEOGRAFIA E ESTATÍSTICA. População estimada: IBGE, Diretoria de Pesquisas, Coordenação de População e Indicadores Sociais, Estimativas da população residente com data de referência $1^{\circ}$ de julho de 2018 . Disponível em:

https://cidades.ibge.gov.br/brasil/mg/januaria/panorama

>. Acesso em: 25 set. 2018.

IBGE - INSTITUTO BRASILEIRO DE GEOGRAFIA E
ESTATÍSTICA. PRODUÇÃO AGRÍCOLALAVOURA TEMPORÁRIA (2017). Disponível em:<https://cidades.ibge.gov.br/brasil/mg/januaria/pesqui sa//pesquisa/14/10193>. Acesso em: 10 set. 2018.

INMET - INSTITUO NACIONAL DE METEOROLOGIA. Banco de dados meteorológicos para ensino e pesquisa. Disponível em: <http://www.inmet.gov.br/portal/index.php?r=bdmep/b dmep>. Acesso em: 02 set. 2018.

PASSOS, M.L.V.; ZAMBRZYCKI, G.C.; PEREIRA, R.S. BALANÇO HÍDRICO CLIMATOLÓGICO E CLASSIFICAÇÃO CLIMÁTICA PARA O MUNICÍPIO DE BALSAS-MA. Revista Scientia Agraria, v.18, n.1, p.83-89, 2017.
CUNHA, A. R.; MARTINS, D. Classificação climática para os municípios de Botucatu e São Manuel, SP. Irriga, Botucatu, v.14, n.1, p.1-11, jan./mar. 2009. DOI: http://dx.doi.org/10.1580 09/irriga.2009v14n1p01

PLANO MUNICIPAL DE SANEAMENTO BÁSICO DE JANUÁRIA - PMSB (2014). 164 p. Disponível em:<http://camarajanuaria.mg.gov.br/site/images/projetos /projeto_lei_complementar_002_2014.pdf >. Acesso em: 13 de set. 2018.

RIBEIRO, A. A.; SIMEÃO, M.; SANTOS, A. R. B. Balanço hídrico climatológico para os municípios de Piripiri e São João do Piauí, Piauí, Brasil. Brazilian Journal of Biosystems Engineering, v. 9 (3): 228-235, 2015. http://dx.doi.org/10.18011/bioeng2015v9n3p228235.

SANTOS, G. O.; HERNANDEZ, F. B. T.; ROSSETTI, J. C. Balanço hídrico como ferramenta ao planejamento agropecuário para a região de Marinópolis, noroeste do estado de São Paulo. Revista Brasileira de Agricultura Irrigada, v.4, p.142-149, 2010.

SILVA, A. O.; MOURA, G. B. A.; KLAR, A. E. Classificação climática de Thornthwaite e sua aplicabilidade agroclimatológica nos diferentes regimes de precipitação em Pernambuco. Brazilian Journal of Irrigation and Drainage - Irriga, v. 19, n. 1, p. 46, 2014.

THORTHWAITE, C. W. An approach towards a rational classification of climate. Geographical Review, London, v.38, p.55-94, 1948.

THORTHWAITE, C.W.; MATHER, J.R. The water balance. Publications in Climatology. New Jersey: Drexel Institute of Technology; 1955, 104p. 